INTERNATIONAL JOURNAL
PHARMACEUTICAL SCIENCES
RESEARCH

Received on 06 February, 2011; received in revised form 28 April, 2011; accepted 05 May, 2011

\title{
ANTIHYPERGLYCEMIC AND GLYCOGENESIS EFFECTS OF DIFFERENT FRACTIONS OF BRASSICA OLERACEA IN ALLOXAN INDUCED DIABETIC RATS
}

\author{
M. Asadujjaman ${ }^{1}$, M. S. Hossain ${ }^{1}$, M. R. I. Khan ${ }^{2}$, A. S. M. Anisuzzaman ${ }^{2}$, M. Ahmed ${ }^{2}$ and A. Islam*3 \\ Department of Pharmacy, Atish Dipankar University of Science \& Technology ${ }^{1}$, Dhaka, Bangladesh \\ Department of Pharmacy, University of Rajshahi ${ }^{2}$, Rajshahi, Bangladesh \\ Department of Pharmacy, Bangladesh University ${ }^{3}$, Dhaka, Bangladesh
}

Keywords:

Brassica oleracea,

Fasting blood glucose (FBG),

Liver glycogen,

Intraperitoneally,

Glycogenesis,

Oral glucose tolerance test

(OGTT),

Alloxan

Correspondence to Author:

Dr. Anwarul Islam, Ph. D,

Assistant Professor, Department of Pharmacy, Bangladesh University, 15/1, Iqbal Road, Mohammadpur, Dhaka-1207, Bangladesh

\section{ABSTRACT}

The present work carried out the study to investigate the antihyperglycemic, oral glucose tolerance test (OGTT) and glycogenesis effects of the different fractions (Petroleum ether, ethyl acetate and chloroform) of ethanolic extract of Brassica oleracea. The different fractions of the extract were administered intraperitoneally as a single dose of $150 \mathrm{mg} / \mathrm{kg}$ body weight to alloxan induced as well as glucose induced diabetic rats and found to reduce blood glucose level significantly $(p<0.05)$. The different fractions of Brassica oleracea to the alloxaninduced diabetic rats resulted in the significant elevation of liver glycogen content which was decreased by $49 \%$ in diabetic control. The plant fractions also improve the glucose tolerance in the glucose induced rats. The effects of plant fractions were compared with standard drug metformin. The phytochemical screening tests indicated that the different constituents such as saponins, tannins, triterpenes, alkaloids and flavonoids etc. were present in the plant which has antidiabetic and glycogenesis properties. Thus, this investigation paves the way for plant based diabetic treatment and indicates that various fractions (Petroleum ether, ethyl acetate and chloroform) of the methanolic extract of Brassica oleracea have favorable effect in bringing down the severity of diabetes, enhancing glycogenesis activity by increasing the cellular uptake of glucose and also improving glucose tolerance activity.
INTRODUCTION: Diabetes mellitus is a metabolic disorder in the endocrine system. This dreadful disease is found in all parts of the world and is becoming a serious threat to mankind health. Diabetes is a chronic disorder in metabolism of carbohydrates, proteins, and fat due to absolute or relative deficiency of insulin secretion with/without varying degree of insulin resistance. According to World Health Organization projections, the prevalence of diabetes is likely to increase by $35 \%$ by the year $2025^{1}$.
Recently, the treatment of diabetes mainly involves a sustained reduction in hyperglycemia by the use of biguanides, thiazolidinediones, sulfonylureas Dphenylalanine and $\alpha$-glucosidase inhibitors in addition to insulin. However, due to unwanted side effects the efficacies of these compounds are debatable and there is a demand for new compounds for the treatment of diabetes ${ }^{2,3}$. Hence plants have been suggested as a rich, as yet unexplored source of potentially useful antidiabetic drugs. Many traditional plants treatment for diabetes are used throughout the World. 
Plant drugs and herbal formulations are frequently considered to be less toxic and free from side effects than synthetic one ${ }^{4}$. The anti-hyperglycemic effect of these plants are for their ability to restore the function of pancreatic tissues by increasing insulin output or inhibit the intestinal absorption of glucose or to the facilitation of metabolites in insulin dependant processes. Hence, treatment with herbal drugs has an effect on protecting $b$-cells and smoothing out fluctuation in glucose levels ${ }^{5}$.

Bangladesh is full of medicinal plants, which are used by the people for the treatment of various diseases even at this modern era. In Bangladesh about 5 million people are affected with diabetes for various reasons, in recent years the popularity of complementary medicines has increased. Dietary measures and traditional plant therapies as prescribed by Ayurvedic and other indigenous systems of medicine have been used commonly in India ${ }^{6}$.

Brassica oleracea (Family-Brassicaceae) is a species of Brassica native to Coastal Southern and Western Europe, where its tolerance of salt and lime but intolerance of competition from other plants typically restricts its natural occurrence to limestone sea cliffs. It has similar composition as other Brassica vegetables 7. Aqueous extract Brassica oleracea is reported to have antidiabetic activity in alloxan induced diabetic modellts ${ }^{8}$. Thus, its leaves are advocated in the management of diabetes mellitus. Here we investigated the antidiabetic effects of petroleum ether, ethyl acetate and chloroform partitionates of ethanolic extract of Brassica oleracea leaves in normal and alloxan induced diabetic rats.

\section{MATERIALS AND METHODS:}

Plant Materials: Fresh leaves of Brassica oleracea (Local name- Cabbage) were collected from medicinal plant garden, Department of Pharmacy, University of Rajshahi, Rajshahi, Bangladesh and various parts of the locality. After thorough washing the leaves were dried completely under mild sun and ground in electric grinder into a coarse powder. The plants were authenticated by Mr. A.H.M. Mahbubur Rahman, Department of Botany, University of Rajshahi, Bangladesh.
Preparation and fractionation of Crude Extracts: The crude extract was obtained through cold extraction process. The coarse powder was submerged in ethanol and allowed to stand for 10 days with occasional shaking and stirring. When the solvent became concentrated the alcohol content was filtered through cotton and then through filter paper (What man filter paper no. 1). Then the solvent was allowed to evaporate using rotary evaporator at temperature 40$45^{\circ} \mathrm{C}$. Thus, the highly concentrated crude extract was obtained. That was then fractionated using petroleum ether, ethyl acetate and $\mathrm{CHCl}_{3}$. The solvents of these fractions were evaporated by rotary evaporator and then dried under mild sun. The dried fractions of extract were then preserved in the freeze for the experimental uses ${ }^{9}$.

Drugs and chemicals used: The standard drug metformin was the generous gift samples from Square Pharmaceuticals Ltd., Pabna Bangladesh. Alloxan was purchased from Sisco Research Laboratories Pvt. Ltd. Mumbai, India. Glycogen test diagnostic kit was otoluidine reagents. Dimethyl sulfoxide (DMSO) was purchased from Loba Chemie, Bombay, India and used to dissolve metformin and the different fractions of extract of Brassica oleracea since these substances are insoluble in water and other available inert solvents ${ }^{10}$.

\section{Phytochemical Screening Methods:}

The following Phytochemical screening methods were used for the tests: ${ }^{11}$

Test for saponins: $300 \mathrm{mg}$ of extract in $5 \mathrm{ml}$ water was boiled for two minutes. Mixture was cooled, mixed vigorously and left for three minutes. The formation of frothing indicated the presence of saponins.

Test for tannins: To an aliquot of the extract added sodium chloride to make to $2 \%$ strength. This was filtered and mixed with $1 \%$ gelatin solution. Precipitation indicated the presence of tannins.

Test for triterpenes: $300 \mathrm{mg}$ extract mixed with $5 \mathrm{ml}$ chloroform and warmed for 30 minutes. To the chloroform solution small volume of concentrated sulfuric acid was added and mixed properly. The appearance of red color indicated the presence of triterpenes. 
Test for alkaloids: $\mathbf{3 0 0} \mathrm{mg}$ extract was digested with 2 molar $\mathrm{HCl}$. The acidic filtrate was mixed with amyl alcohol at room temperature and the alcoholic layer was examined. Pink color indicated the presence of alkaloids.

Test for flavonoids: The presence of flavonoids was determined using $1 \%$ aluminium chloride solution in methanol, concentrated $\mathrm{HCl}$ magnesium turnins and potassium hydroxide solution. Red color indicated the presence of flavonoids.

\section{Preparation of dosage of active drug and plant extract:}

Metformin: Metformin was in microcrystalline form and freely soluble in water. The dosage was prepared in solution form using sterilized water in such a concentration that, each $0.1 \mathrm{ml}$ of solution contained metformin according to the dose of $150 \mathrm{mg} / \mathrm{kg}$ body weight since metformin is effective in such dose.

Brassica oleracea: The fractionated extracts of Brassica oleracea were dissolved in $99 \%$ DMSO to prepare the solution where each $0.1 \mathrm{ml}$ contained Brassica oleracea according to the dose of $150 \mathrm{mg} / \mathrm{kg}$ body weight ${ }^{12}$. $0.1 \mathrm{ml}$ of each solution was administered intraperitoneally to every $100 \mathrm{gm}$ body weight of the rats during treatment to achieve required dose of fractions of plant extract.

Selection of animals: A total number of 50 long-Evans male rats weighing about 150-180 gm, age 2 months were purchased from animal house of International Centre for Diarrhoeal Disease Research, Bangladesh (ICDDR, B). Prior to commencement of the experiment all the rats were acclimatized to the new environmental condition for a period of one week. During the experimental period the rats were kept in a well ventilated animal house at room temperature of $25^{\circ} \mathrm{C}$ and were supplied with standard pellets supplied from ICDDR, B and fresh drinking water. All the rats were kept in cages with wide square mesh at bottom to avoid coprophagy and maintained with natural 12 hour light and dark cycle ${ }^{13}$.

Grouping of experimental rats: 60 long-Evans male rats were randomly assigned into 12 groups, 5 rats in each group.
Group 1 Normal Control

Group 2 Diabetic Control

Group 3 Diabetic+ Metformin (150mg/kg body wt.)

Group 4

Group 5

Group 6

Group 7

Group 8

Group 9

Group 10

Group 11

Group 12

Diabetic+ Petroleum ether fraction BO $(150 \mathrm{mg} / \mathrm{kg}$ body wt.)

Diabetic+ Ethyl acetate fraction BO $(150 \mathrm{mg} / \mathrm{kg}$ body wt.)

Diabetic+ Chloroform fraction BO $(150 \mathrm{mg} / \mathrm{kg}$ body wt.)

Normal control

Glucose control

Glucose+ Metformin (150mg/kg body wt.)

Glucose+ Petroleum ether fraction BO $(150 \mathrm{mg} / \mathrm{kg}$ body wt.)

Glucose+ Ethyl acetate fraction BO $(150 \mathrm{mg} / \mathrm{kg}$ body wt.)

Glucose+ Chloroform fraction BO $(150 \mathrm{mg} / \mathrm{kg}$ body wt.)

Experimental induction of Diabetes: Group 1 animals were used for normal control receives only vehicle (DMSO). Groups 2-6 animals were allowed to fast for $12 \mathrm{hrs}$ and were induced diabetic by injection intraperitoneally a freshly prepared solution of alloxan (110 $\mathrm{mg} / \mathrm{kg}$ body wt.) in normal saline after base line glucose estimation was done. The alloxan treated animals were allowed to feed over night to overcome drug induced hypoglycemia. After 48 hours blood glucose content was measured by using Bioland G- 423 test meter (Bioland, Germany) using blood sample from the tail vein of the rats. When the condition of diabetes was established animals with blood glucose levels above $11.1 \mathrm{~m} \mathrm{~mol} / \mathrm{L}$ was selected for the study. Group 8 animal were used for glucose control receives only glucose and groups 8-12 animals were allowed to fast for 12 hrs were rendered diabetic by oral administration of glucose for the test of OGTT ${ }^{14}$.

Antihyperglycemic effect of Plant Extracts: The groups 2-6 were prepared for resting antihyperglycemic effect after alloxan induction. All the rats were starved at water for 16 hours and then were tested for baseline glucose level. The group 2 was selected for diabetic control group which does not receive extract or metformin. The group 3 stands for metformin control group which was administered metformin intraperitoneally at a dose of $150 \mathrm{mg} / \mathrm{kg}$ body weight. The groups 4-6 received the different fractions of extract of the plants. The blood glucose level was then tested by using glucometer (Bioland Glucometer, 
Germany). In this case, the blood was collected by picking the tail vein in $0,2,6,16$ and 24 hours after drug and plant extract administration ${ }^{15}$.

Estimation of glycogen content in liver: The liver was collected from hearts after sacrificing the rats of the groups 1-6 which were used for antihyperglycemic experiment. Then liver glycogen concentrations were analyzed by taking absorbance by UV spectrophotometer using o-toluidine reagent diagnostic kits. This test utilizes the o-toluidine-glucose coupling reaction for the estimation of glycogen after trichloroacetic acid (TCA) extraction, precipitation by alcohol and hydrolysis ${ }^{16}$.

Oral Glucose Tolerance Test: Groups 7-12 were selected for OGTT test after starving at water for 16 hours. The base line glucose level was measured by glucometer ${ }^{17}$. Group 7 stands for normal control group. Group 8 received glucose. Group 9 was treated with metformin ( $150 \mathrm{mg} / \mathrm{kg}$ body weight). The extracts of different fractions were then administered intraperitoneally at the dose of $150 \mathrm{mg} / \mathrm{kg}$ body weight. $2 \mathrm{ml}$ glucose ( $2 \mathrm{gm} / \mathrm{kg}$ body weight) solution was administered orally by intra gastric tube. The blood glucose level was then tested by using glucometer (Bioland Glucometer, Germany). In this case, the blood was collected by picking the tail vein in $0,30,60,90,150$ and 270 minutes $^{18}$.

Statistical Analysis: The results were expressed as mean \pm S.E.M using Graph Pad Prism (version 4.0) computer program (Graph pad Software San Diego, CA, USA). We used a one-way analysis of variance (ANOVA), followed by Scheffe's post-hoc test or students paired or unpaired t-test where appropriate. The statistical method applied in each analysis was described in each figure. Results were considered to be significant when $p$ values were less than $0.05(p<0.05)$.

RESULTS: The effect of the different fractions of methanolic extract of Brassica oleracea on the fasting blood glucose (FBG) level, glycogen content in liver and oral glucose tolerance test (OGTT) were investigated in the alloxan-induced diabetic rats using metformin as standard antidiabetic agents.
Effect of different fractions of Brassica oleracea on Fasting Blood Glucose (FBG) level in Diabetic Rats: The mean blood glucose concentration of control and different fractions of $B$. oleracea -treated animals were estimated on the $2,6,16$, and 24 hours, respectively as shown in Fig 1.Their baseline glucose concentrations was also measured. In case of alloxan induced diabetic rats metformin reduced blood glucose level to $72 \%$, $61 \%, 51 \%$ and $33 \%$ in 2, 6, 16, and 24 hours, respectively. In case of petroleum ether fraction reduced blood glucose level to $77 \%, 50 \%, 37 \%$ and $37 \%$ in $2,6,16$, and 24 hours, respectively. Ethyl acetate fraction reduced blood glucose level to $92 \%, 65 \%, 49 \%$ and $46 \%$ in 2,6,16, and 24 hours, respectively. $\mathrm{CHCl}_{3}$ fraction reduced blood glucose level to $86 \%, 61 \%, 42 \%$ and $38 \%$ in $2,6,16$, and 24 hours, respectively. The results were compared with diabetic control group.

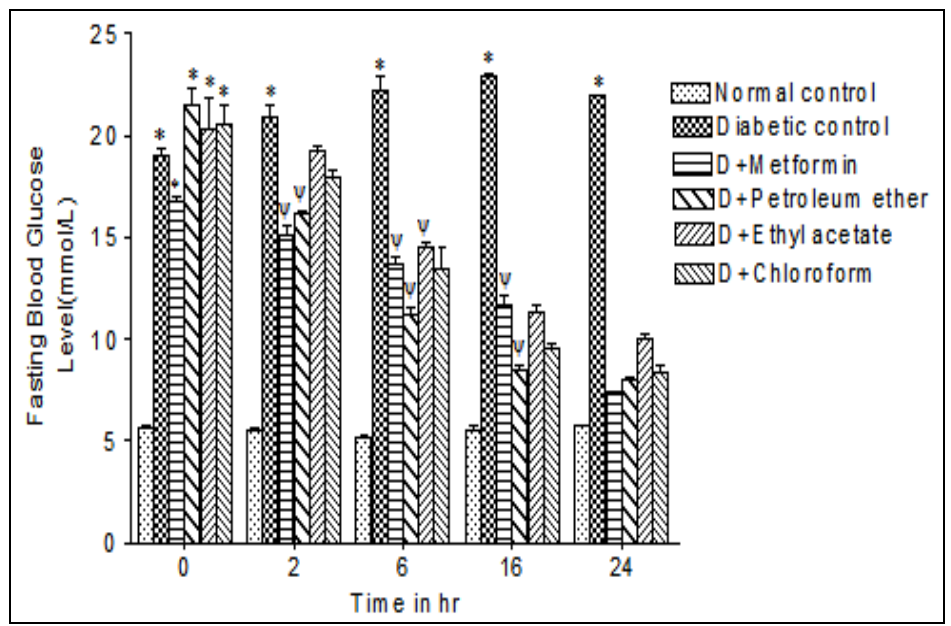

FIG. 1: EFFECT OF DIFFERENT FRACTIONS OF B. OLERACEA ON THE FBG LEVEL ON DIABETIC RATS COMPARED TO NORMAL RATS

*indicates significant change in blood glucose level compared with normal control group $(p<0.05) . \psi$ indicates significant changes in FBG level in diabetic rats after treatment $(p<0.05)$. The results are expressed as means \pm SEM

Effect of Experimental Plant Fractions on the level of Glycogen in Diabetic Rats: In this study, it was found that the level of glycogen in liver was reduced to $49 \%$ in diabetic rats as compared to the normal control group. In the treatment of diabetic rats with metformin standard, petroleum ether, ethyl acetate and $\mathrm{CHCl}_{3}$ fractions of Brassica oleracea, the level of glycogen content was improved to $61 \%, 86 \%, 66 \%$ and $95 \%$, respectively as shown in the Fig. 2 . The results were compared with normal control group. 


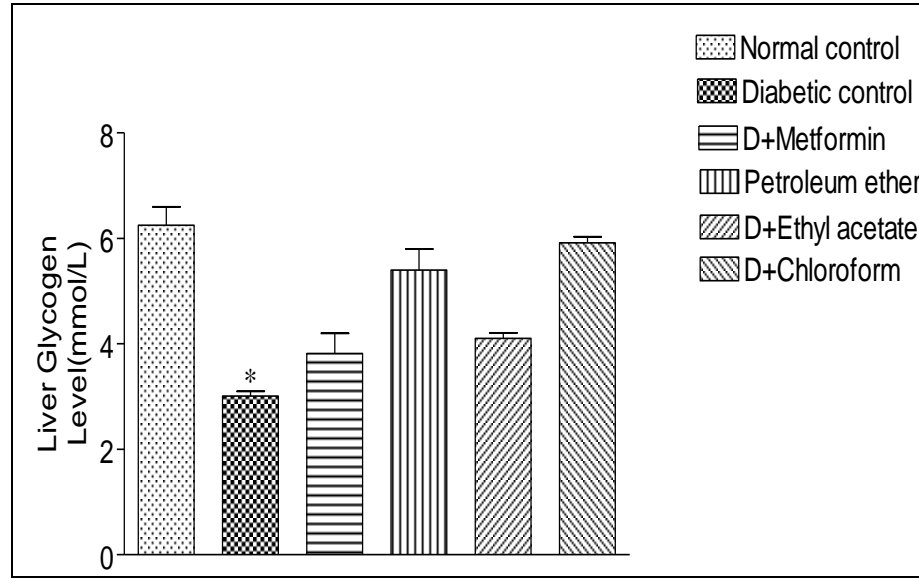

FIG. 2 EFFECT OF DIFFERENT FRACTIONS OF B. OLERACEA ON THI GLYCOGEN LEVEL IN LIVER ON DIABETIC RATS COMPARED TC NORMAL RATS

* indicates significant difference $(p<0.05)$ from without alloxan treated time control. The results were expressed as means \pm SEM.

Effect of different fractions of $B$. oleracea on Fasting Blood Glucose (FBG) level in the Glucose- induced Hyperglycemic Rats: In case of the effect of different fractions of Brassica oleracea petroleum ether fraction reduced blood glucose level to $85 \%, 73 \%$ and $75 \%$ in 30,60 and 90 minutes, respectively. $\mathrm{CHCl}_{3}$ fraction reduced blood glucose level to $79 \%, 62 \%$ and $67 \%$ in 30, 60 and 90 minutes, respectively. Ethyl acetate fraction reduced blood glucose level to $88 \%, 71 \%$ and $67 \%$ in 30, 60 and 90 minutes, respectively as shown in the Fig. 3. The results were compared with glucose induced group.

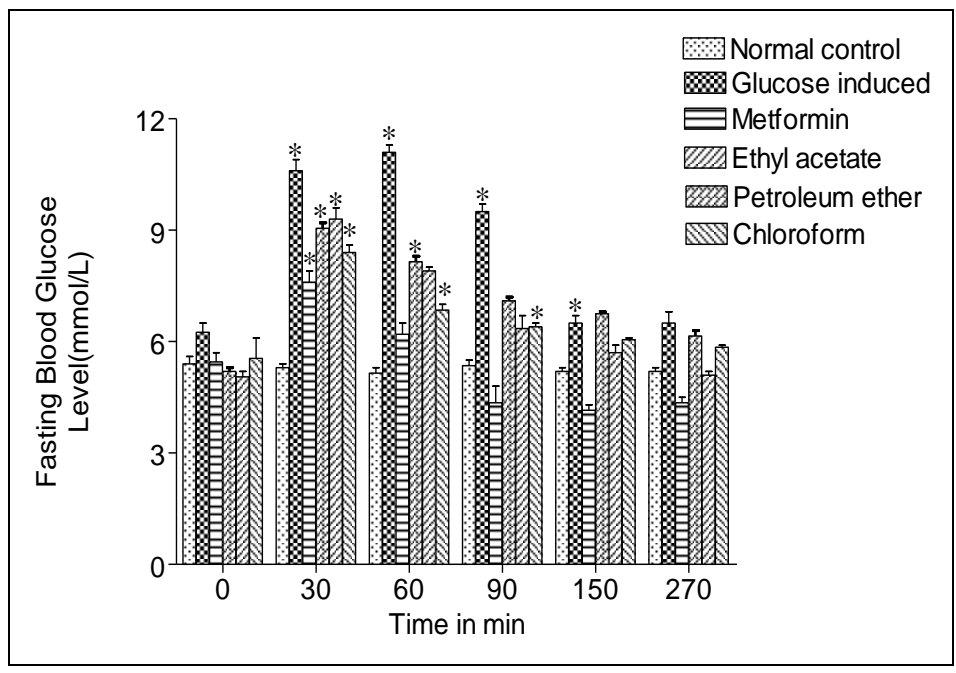

FIG. 3 EFFECT OF DIFFERENT FRACTIONS OF B. OLERACEA ON THE GLUCOSE-INDUCED HYPERGLYCEMIA IN NORMAL RATS

* indicates significant changes in FBG level compared to normal rats after treatment $(p<0.05)$. The results are expressed as means \pm SEM.
Phytochemical Screening: The phytochemical screening tests indicated the different constituents such as saponins, tannins, triterpenes, alkaloids and flavonoids were present in the plant $B$. oleracea which have the antidiabetic and glycogenesis properties. The results are summarized in Table 1.

TABLE 1: THE PHYTOCHEMICAL CONSTITUENTS OF THE EXPERIMENTAL PLANT FRACTIONS OBTAINED BY PHYTOCHEMICAL SCREENING TESTS

\begin{tabular}{cccccc} 
Partitionates & Saponins & Tannins & Triterpenes & Alkaloids & Flavonoids \\
\hline Pet-ether & + & + & - & + & + \\
Ethyl acetate & + & + & + & + & + \\
Chloroform & + & + & - & - & + \\
\hline
\end{tabular}

$(+)=$ Present; $(-)=$ Absent

DISCUSSION: Plant medicines have a long history as treatment for diabetes. With a disturbing rise in the prevalence of this metabolic disease and associated healthcare costs, interest in alternative or complementary therapies has grown ${ }^{19}$. The pathogenesis of diabetes mellitus and the possibility of its management by existing therapeutic agents without any side effects have stimulated great interest in recent years ${ }^{20}$.

In this study the different fractions of ethanolic extract of Brassica oleracea reduced blood glucose level significantly in the hyperglycemic rats. The significant antihyperglycemic activity of petroleum ether, ethyl acetate and chloroform fractions of Brassica oleracea as shown in Fig. 1 may be due to the presence of hypoglycemic saponins, tannins, triterpenes, alkaloids and flavonoids etc. (Table 1). Brassica oleracea lowered hyperglycemia and it may be useful for the treatment of diabetes and associated complications ${ }^{21}$. It could be envisaged that the plant extracts may also contain some biomolecules that may sensitize the insulin receptor to insulin or stimulates the $b$-cells of islets of langerhans to release insulin which may finally lead to improvement of carbohydrate metabolizing enzymes towards the re-establishment of normal blood glucose level.

In diabetes, the glycogen content of the skeletal muscles and liver, markedly depleted ${ }^{22}$ and the reduced levels of hepatic glycogen are due to inadequate insulin secretion, which results in the 
inactivation of glycogen synthatase system ${ }^{23}$. B. oleracea extracts lowered blood glucose levels and restored renal function and body weight loss. In addition, $B$. oleracea extracts attenuated the adverse effect of diabetes on malondialdehyde, glutathione and superoxide dismutase activity ${ }^{24}$.

In the present study decreased levels of glycogen and glycogen synthase were observed in diabetic control rats. It may be due to insufficient secretion of insulin in the diabetic state as stated earlier. It was reported that the treatment with Brassica oleracea the accumulation of glycogen and its contents raised to that of normal level (Fig. 2). This may be due to the presence of hypoglycemic saponins, tannins, triterpenes, alkaloids and flavonoids etc., (Table 1) and activation of glycogen synthatase system.

Intraperitoneal administration of petroleum ether, ethyl acetate and $\mathrm{CHCl}_{3}$ fractions of Brassica oleracea recovered this problem and help in cellular uptake of glucose and subsequently synthesis the liver glycogen again by the modulatory effects of constituents of the fractions through induction of insulin secretion. Decreased in the activities of the enzymes involved in glucose homeostasis in liver and kidney such as hexokinase has been reported in diabetic animals resulting in depletion of liver and muscle glycogen content ${ }^{22}$. Treatment with plant extracts might increase the level of enzyme to the control level indicating an over-all increase in glucose influx.

Oral glucose tolerance test (OGTT) measures the body's ability to use glucose, the body's main source of energy ${ }^{17}$. Brassica oleracea is used as antidiabetic plant in traditional medicine ${ }^{25}$. The extracts of Brassica oleracea has been reported to produce fall in fasting blood glucose (FBG) level and improve glucose tolerance in rats. In our study, it was observed that various fractions have also hypoglycemic effect in glucose induced hyperglycemic rats. The fractions of plant extract enhanced glucose utilization. So the blood glucose level was significantly reduced in the glucose loaded rats (Fig. 3). This may be due to the presence of hypoglycemic saponins, tannins, triterpenes, alkaloids and flavonoids etc., (Table 1 ).
CONCLUSION: Our preliminary phytochemical analysis has indicated that flavonoids and alkaloids have been reported to exert potent hypoglycemic and hypolipidemic effects. Thus, in the light of our pharmacological studies it was observed that the administration of plant fractions of Brassica oleracea extract demonstrated antihyperglycemic activity by producing significant restoration of blood glucose level as well as illustrated some beneficial effects such as increase liver glycogen synthesis activity by cellular uptake of glucose in alloxan-induced diabetic rats and also improvement of oral glucose tolerance in glucose induced diabetic rats. Further comprehensive pharmacological investigations are needed to elucidate the exact chemical compounds responsible for antihyperglycemic activity, liver glycogen synthesis activity as well as improvement of oral glucose tolerance and also their exact mechanism of actions. However this study will pave the way for plant based specific treatment of diabetes avoiding the complications of artificial drug substances.

\section{ACKNOWLEDGEMENT:}

The authors would like to thank the Department of Pharmacy, University of Rajshahi, Bangladesh for providing lab facilities and International Centre for Diarrhoeal Disease Research, Bangladesh (ICDDR, B) for supplying rats for the research work.

\section{REFERENCES:}

1. Boyle JP, Honeycutt AA, Narayan KM, Hoerger TJ, Geiss LS, Chen $\mathrm{H}$, Thompson TJ: Projection of diabetes burden through 2050: Impact of changing demography and disease prevalence in the U.S. Diabetes Care, 2001; 24(11): 1936-1940.

2. U.K Prospective Diabetes Study Group: Overview of six years therapy of type 2 diabetes: a progressive disease: diabetes, 1995; 44: 1249-1258.

3. Moller DE: New drug targets for type 2 diabetes and the metabolic syndrome. Nature, 2001; 414: 821-827.

4. Bailey CJ, Day C: Traditional treatments for diabetes: Diabetes Care, 1989; 12: 553-564.

5. Jia W, Gao WY, Xiao PG: Antidiabetic drugs of plant origin used in China: Composition, pharmacology, and hypoglycemic mechanisms. Zhonggue Zhong Yao Za Zhi, 2003; 28: 108-113.

6. Warrier P K, Nambiar VPK, Ramankutty C, Vasudevan Nair R: Indian Medicinal Plants-a compendium of 500 species. $2^{\text {nd }}$ Edn. Orient Longman Pvt. Ltd. Chennai, India, 1996; pp311-315

7. Gross D: Indole Phytoalexins from Brassica oleracea var. gongylodes. Planta Medica, 1994; 59: A-618.

8. Srinivas P, Patil PA: Hypoglycemic activity of Brassica oleracea var. gongylodes in normal and diabetic rats. Fitoterapia LXIV, 1993; 4: 301-303. 
9. Hossain $\mathrm{M} S$, Ahmed $\mathrm{M}$, Islam $\mathrm{A}$ : Hypolipidemic and hepatoprotective effects of different fractions of ethanolic extract of immature leaves of Mangifera indica (Linn.) in alloxan induced diabetic rats. International Journal of Pharmaceutical Sciences and Research, 2010; 1(11): 132-138.

10. Akhtar MA, Rashid M, Ibne-Wahed MI, Islam MR, Shaheen SM, Islam MA, Amran MS, Ahmed M: Comparison of long-term antihyperglycemic and hypolipidemic effects between Coccinia cordifolia (Linn) and Catharanthus roseus (Linn) in Alloxan induced diabetic rats. Res. J. of Med. and Med. Scien., 2007; 2 (1): 29-34.

11. Nayak BS, Pinto perira LM: Catharanthus roseas flower extract has wound-healing activiry Sprague Dawley rats. $B M C$ Complement alternative Medicine, 2006; 6: 41.

12. Gosh S, Suryawanshi SA: Effects of Vinca rosea extracts in the treatment of alloxan diabetes in male albino rats. Indian J. Exp. Biol., 2001; 39: 748-759.

13. Khan MRI, Islam MA, Hossain MS, Asadujjaman M, Wahed MII, Rahman BM, Anisuzzaman ASM, Shaheen SM, Ahmed M: Antidiabetic Effects of the Different Fractions of Ethanolic Extracts of Ocimum sanctum in Normal and Alloxan Induced Diabetic Rats. Journal of Scientific Research, 2010; 2(1): 158168.

14. Hossain MS, Asadujjaman M, Khan MRI, Ahmed M, Islam A: Antidiabetic and glycogenesis effects of different fractions of methanolic extract of Momordica charantia (Linn.) in alloxan induced diabetic rats. International Journal of Pharmaceutical Sciences and Research, 2011; 2(2): 404-412.

15. Hossain MS, Khan MRI, Anisuzzaman ASM, Ahmed M, Amran MS, Islam A: Antidiabetic and glycogenesis effects of different fractions of ethanolic extract of leaves of $M$. indica (Linn.) in normal and alloxan induced diabetic rats. Journal of Medical Science, 2010; 10(4): 80-86.

16. Klara tarnoky, Nagy S: Spectrophotomectric determination of glycogen with o-toluidine. Clin. Chim. Acta, 1963; 8(4): 627-628.
17. Du-Vigneaud V, Karr WG: Carbohydrate utilization, rate of disappearance of D-glucose from the blood. J. Biological Chem., 1925; 66: 281-300.

18. Islam MA, Akhtar MA, Khan MRI, Hossain MS, Khurshid Alam AHM, Wahed MII, Amran MS, Rahman BM, Ahmed M: Oral glucose tolerance test (OGTT) in normal control and glucose induced hyperglycemic rats with Coccinia cordifolia L. and Catharanthus roseus L. Pak. Jr. of Pharmaceutical Sciences, 2009; 22(4): 402-404.

19. Islam MA, Akhtar MA, Khan MRI, Hossain MS, Alam MK, Wahed MII, Rahman BM, Anisujjaman ASM, Shaheen SM, Ahmed M: Antidiabetic and hypolipidemic effects of different fractions of Catharanthus roseus (Linn.) on normal and streptozotocininduced diabetic rats. Journal of Scientific Research, 2009; 1(2); 334-344.

20. Bailey CJ: New pharmacological approaches to glycemic control. Diabetes Review, 1999; 7: 94-113.

21. Rasal VP, Shetty BB, Sinnathambi A, Yeshmaina S, Ashok P: Antihyperglycaemic and Antioxidant Activity of Brassica Oleracea in Streptozotocin Diabetic Rats. The Internet Journal of Pharmacology. 2006; Volume (4), Number (2).

22. Grover JK, Vats V, Rathi SS: Antihyperglycemic effect of Eugenia jambolana and Tinospora cardifolia in experimental diabetes and their effects on key metabolic enzymes involved in carbohydrate metabolism. J. Ethnopharmacol., 2002; 73: 461470.

23. Sumana G, Suryawanshi SA: Effect of Vinca rosea extracts in treatment of alloxan diabetes in male albino rats. Indian J. Exp. Biol., 2001; 39: 748-758.

24. Hazem A, Kataya H, Alaa Eldin A: Hamza. Red Cabbage (Brassica oleracea) Ameliorates Diabetic Nephropathy in Rats. eCAM., 2008; 5(3): 281-287.

25. Edwin J, joshi SB, Jain DC: Diabetes and herbal medicine. Iranian Journal of Pharmacology and therapeutics, 2008; 7: 97-106. 